\title{
Analysis of the Mechanism of Longitudinal Flutter of Single Wheel-Set and Related Influence ${ }^{*}$
}

\author{
Wengwu Fang ${ }^{1}$, Shihui Luo ${ }^{1}$, Weihua $\mathrm{Ma}^{1}$, Zhenjun $\mathrm{Li}^{2}$ \\ ${ }^{1}$ Department of Traction Power State Key Laboratory, University of Southwest Jiaotong, Sichuan Province, China \\ ${ }^{2}$ Department of Public Administration, University of Southwest Jiaotong, Sichuan Province, China \\ fww20070904@gmail.com,shluo@home.swjtu.edu.cn
}

\begin{abstract}
The purpose of the study is to analyse the mechanism of longitudinal flutter and related influence by establishing a simplified single wheel-set dynamic model of locomotive. The phenomenon of wheel-set longitudinal flutter is observed at specific speed, after analyse the flutter frequency, found it is nearly the same with wheel set natural vibration frequency, then we put forward a concept of flutter dangerous speed, and a close criterion to calculate the speed is offered. Then discuss the influence of the longitudinal flutter to longitudinal creepage and adhesion utilization coefficient. On this basis, study the impact to the force in wheel/rail contact area and relative sliding at the wheel/rail contact patch; found that the force of wheel/rail contact area was increased significantly; the wheel/rail contact patch relative sliding was quite large, the contact patch adhesion area no longer exists. So we should give more consideration to the vehicle longitudinal influence in the future study.
\end{abstract}

Index Terms - single wheel-set, longitudinal flutter, dynamic

\section{Introduction}

Railway vehicle's longitudinal flutter is due to the wheelset longitudinal flutter, it has become an important reason for abnormal wear. Under normal circumstances a slight out-ofround (OOR) has little effect on vehicle performance [1]. However, many turnings wheel repair is due to fast wheel outof-round, even cause tread spalling [2], affecting ride comfort and operate reliability. Literature [3-4]proposed measures to reduce wheel tread spalling. The research on $\mathrm{DF}_{21}$ meter gauge diesel locomotive as well as some raising speed locomotive [5-6] found that this phenomenon has great relationship with the wheel longitudinal flutter. Since the axial rod of middle axle in $\mathrm{DF}_{21}$ locomotive use small stiffness, middle wheel sets longitudinal vibration reduce significantly, no peeling occurred, and running very well. For a long time, the railway vehicle dynamics focuses on lateral issues because of wheel/rail lateral self-excited vibration [7]. Over the past decade, the research on the vertical dynamics with the track structure, noise, vehicle-line-bridge, the impact of rail corrugation has carried out detailed [8]. But the current design for railway vehicles at home and abroad, the majority just consider lateral and vertical vibration characteristics, the longitudinal motion was ignored [9], the elastic positioning wheel sets longitudinal vibration characteristics are rarely considered [10].The longitudinal vibration caused wheel/rail tangential load changes which may lead wheel/rail interface stick-slip vibration [11-12]. As for how it happened is not known, in other words, the mechanism of longitudinal flutter is still unknown.

In this paper, by establishing a single wheel set model, discover the wheel set longitudinal flutter, and determine the wheel set flutter frequency, then gives a closer criterion to flutter frequency. Analyse the relationship between longitudinal flutter and forward speed, adhesion utilization factor, then proposed a concept of flutter dangerous speed and estimated. On this basis, study the influence of longitudinal flutter to the force in wheel-rail contact area and the relative sliding of wheel/rail contact patch.

\section{A Simplified Model of Single Wheel-set}

A. Single wheel set model

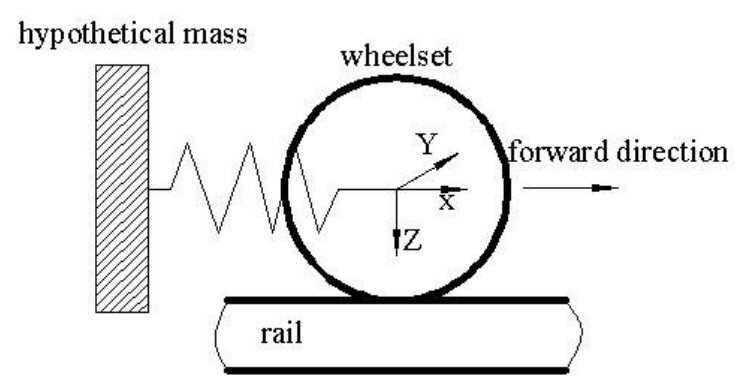

Fig.1 model of single wheel-set

Wheel set has six degrees of freedom, in the model we establish a hypothetical mass, which role is: on the one hand to simulate the positioning base of the wheel-set, the other hand is to increase the critical speed of the wheel set hunting speed, shown as Fig.1.

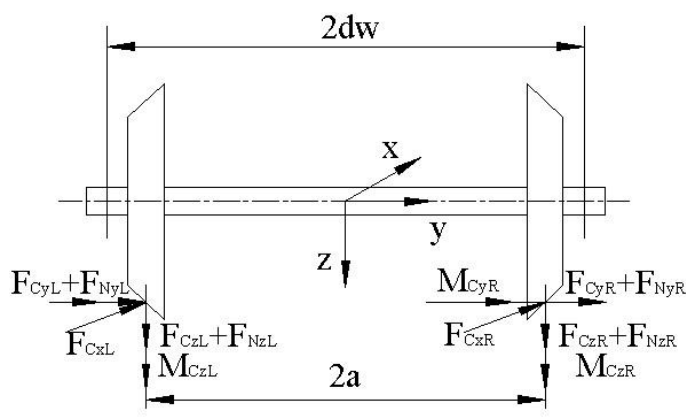

Fig.2 force of single wheel-set

\footnotetext{
* This work is supported by National Natural Science Foundation of China (Grant No: 51005190).
} 
Fig.2 is the force analysis of wheel-set, according to the force obtained differential equations:

$$
\begin{gathered}
m \ddot{x}_{w}=F_{C x L}+F_{C x R}+F_{S U S P x} \\
m \ddot{y_{w}}=F_{C y L}+F_{C y R}+F_{y L}+F_{y R}+F_{S U S P y} \\
m \ddot{z_{w}=} F_{C Z L}+F_{C Z R}+F_{N Z L}+F_{N z R}+F_{S U S P_{z}}-W \\
I_{y} \ddot{\beta}_{y w}=F_{C y L} r_{L}+F_{C X R} r_{R}+M_{C y L}+M_{C y R} \\
+x_{w L}\left(F_{C Z L}+F_{z L}\right)-x_{w R}\left(F_{C z R}+F_{z R}\right) \\
\ddot{I}_{z} \ddot{\psi}_{w}+I_{y} \dot{\beta}_{w} \dot{\Phi}_{w}=\left(F_{C X L}-F_{C x R}\right) a+M_{C z L}+M_{C z R}+M_{S U S P} \\
\quad+a \psi_{w}\left(F_{C y L}+F_{y L}-F_{C y R}-F_{y R}\right) \\
I_{x} \ddot{\phi}_{w}=I_{y}(x / r) \ddot{\psi}_{w}+r_{R y}\left(F_{C Z R}+F_{N z R}\right)-r_{z}\left(F_{C y R}+F_{N y R}\right) \\
+M_{C y L}+M_{C y R}+M_{S U S P}
\end{gathered}
$$

In the equations, $x_{w}, y_{w}, z_{w}$, namely wheel set central displacement of longitudinal, lateral, vertical, $F_{c}, F$ means creep force and normal force; $F_{S U S P}, M_{S U S P}$ means suspension force and torque; $w$ means axle weight; $\Phi_{w}, \Psi_{w}$ means wheel set roll angle, yaw angle; $a$ means half of left and right wheel/rail contact point; $I_{j}$ means inertia of $j$ direction $(j=x, y$, $z) ; r_{i}$ means radius of rolling circle $(i=L, R)$.

\section{B. Wheel/rail contact relationship}

Wheel/rail contact type use JM3 wear tread and $60 \mathrm{~kg} / \mathrm{m}$, wheel/rail contact geometry is a function of the wheel-set later al sliding.

\section{Parameters of model}

Rolling circle radius of wheel is $500 \mathrm{~mm}$, axle-box longitudinal positioning stiffness is $1.2 \times 10^{7} \mathrm{~N} / \mathrm{m}$,lateral stiffness is set to $6 \times 10^{6} \mathrm{~N} / \mathrm{m}$, vertical damping is $1000 \mathrm{~N} \cdot \mathrm{s} / \mathrm{m}$, the stiffness and damping in the other direction is not set, other parameters shown as Table 1.

Table 1 Relevant model parameters

\begin{tabular}{|c|c|c|c|}
\hline Body & Mass $/ \mathrm{kg}$ & Inertia $(\mathrm{x}, \mathrm{z}) / \mathrm{kg} \cdot \mathrm{m}^{2}$ & Inertia $\mathrm{y} / \mathrm{kg} \cdot \mathrm{m}^{2}$ \\
\hline Wheel-set & 5000 & 400 & 100 \\
\hline hypothetical mass & $1 \times 10^{10}$ & 1 & 1 \\
\hline
\end{tabular}

\section{Track irregularity}

The irregularity of the model can be expressed by the following polynomial:

$$
F(j \Omega)=\frac{b_{0}+b_{1} j \Omega}{a_{0}+a_{1} j \Omega+a_{2}(j \Omega)^{2}}
$$

In the equation, $F(j \Omega)$ is a transfer function of wave filt er, $\Omega$ is function variable, the other variables are non-negative polynomial coefficients.According to polynomial coefficients determined the spatial frequency distribution of track irregular ities.Shown as Fig.3.

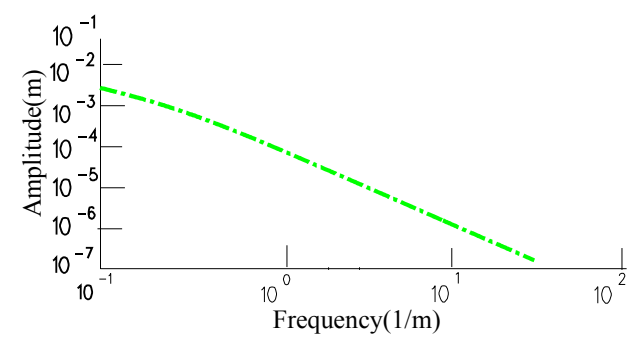

Fig. 3 Track irregularity

\section{Research on Longitudinal Vibration}

\section{A. Longitudinal vibration resonance frequency}

The single wheel-set model hunting speed is $40 \mathrm{~km} / \mathrm{h}$,so we choose the speed $10 \mathrm{~km} / \mathrm{h}, 20 \mathrm{~km} / \mathrm{h}, 30 \mathrm{~km} / \mathrm{h}$ as simulation, the speed refers to nominal forward speed[14], we find it occurs longitudinal flutter at the speed of $20 \mathrm{~km} / \mathrm{h}$, we can see the longitudinal vibration acceleration at the speed $20 \mathrm{~km} / \mathrm{h}$ is far more than the running speed of $10 \mathrm{~km} / \mathrm{h}$ and $30 \mathrm{~km} / \mathrm{h}$.analyse the model root locus found that there is a frequency does not change with speed, further analyse the vibration frequency, find that this frequency is exactly the wheel longitudinal natural frequency, shown in Fig.4.

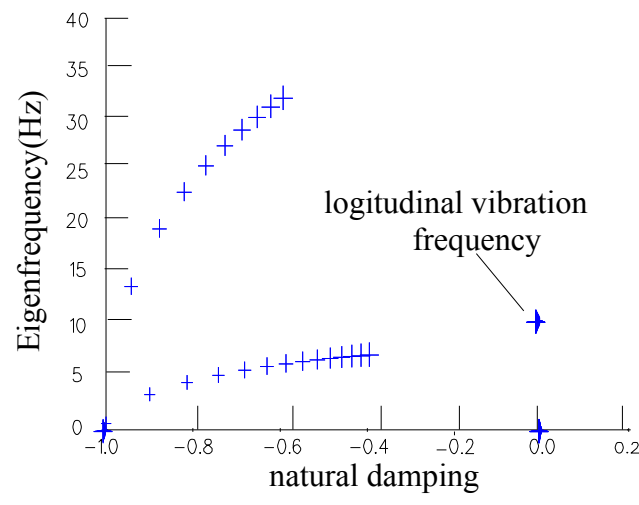

Fig.4 analysis of eigenfrequency

The frequency related with wheel set quality and longitudinal stiffness. According to the work done by Muller, P.C and Schiehlen, W.O [15], we get an approximate estimate of the formula:

$$
f_{0}=\frac{1}{2 \pi} \sqrt{\frac{2 \cdot k_{x}}{m}}
$$

$m$ is the wheel set mass in the equation, $k_{x}$ is axle-box longitudinal positioning stiffness, parameters into the equation:

$$
f_{0}=\frac{1}{2 \pi} \sqrt{\frac{2 \cdot k_{x}}{m}}=\frac{1}{2 \pi} \sqrt{\frac{2 \times 1.2 \times 10^{7}}{5000}}=11 \mathrm{~Hz}
$$

\section{B. Longitudinal flutter velocity}

Fig. 5 is acceleration spectrum at $20 \mathrm{~km} / \mathrm{h}$,there is a peak at $10.8 \mathrm{~Hz}$.Compared with different speed simulation, this frequency vary with the running speed.the external excitation at $20 \mathrm{~km} / \mathrm{h}$ the wheel-set longitudinal frequency is closer to 
longitudinal natural frequency. Moreover, we can regard equation (8) as an approximate criterion whether a vehicle will flutter before it runs.

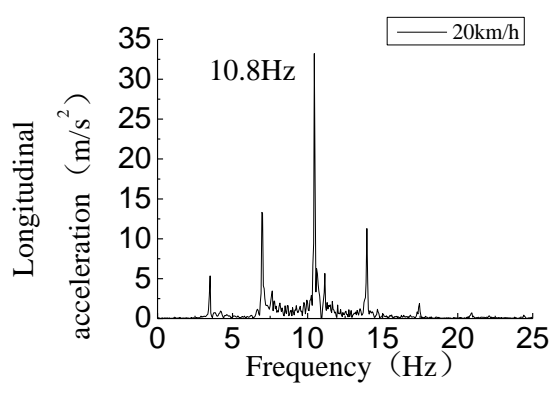

Fig.5 acceleration frequency spectrum

Currently, this formation mechanism which cause the wheel-set longitudinal flutter is not clear[16].Since wheel set longitudinal flutter or not is specific at different speed,we can get longitudinal flutter has a relationship with velocity.The frequency change with speed can be expressed:

$$
f_{v}=\frac{v / 3.6}{2 R}
$$

In the equation, $R$ is the radius of the rolling circle; $v$ is the forward speed of the wheel-set.

As we all know, the longitudinal natural frequency of the wheel-set is the whole multiple $n$ of the longitudinal vibration frequency who changes with velocity, the wheel-set is more likely to occur the longitudinal flutter, this speed defined as flutter dangerous speed. Obviously, when $n=1$, the flutter dangerous speed reach to maximum, as the critical speed in the model is $40 \mathrm{~km} / \mathrm{h}$, so choose $n=2$. Then according to the equation (7) and (8), obtain flutter dangerous speed:

$$
\begin{aligned}
& v=3.6 \times 2 R \cdot f_{v}=7.2 R \times \frac{f_{0}}{n} \\
& v=7.2 \times 0.5 \times \frac{10.8}{2}=19.4 \mathrm{~km} / \mathrm{h}
\end{aligned}
$$

It is a little deviation with the nominal forword speed 20 $\mathrm{km} / \mathrm{h}$, when examine longitudinal velocity component,once ignored by us,find it is $0.6 \mathrm{~km} / \mathrm{h}$,so we can get flutter dangerous speed is the vector difference between nominal forward speed and longitudinal velocity component.

\section{Longitudinal flutter on the longitudinal creepage and the coefficient of adhesion utilization}

Analyse the change of longitudinal creepage and adhesion utilization coefficient,value of the longitudinal creepage at $20 \mathrm{~km} / \mathrm{h}$ is far more than the other speeds.Its longitudinal creepage dynamic change is up to $400 \%$.Seen in the Fig.6.in Fig.7,adhesion coefficient often reach saturation at $20 \mathrm{~km} / \mathrm{h}$,it means wheels slipping,which will not only reduce the performance of vehicles, but also damage the wheel tread[17].If railway vehicle long-run with longitudinal flutter,then wheel-rail contact patch is at a strong stick-slip vibration, which greatly increase the wheel/rail contact patch dynamic load, serious deterioration the wheel/rail interface and lead to the wheels wear[18].

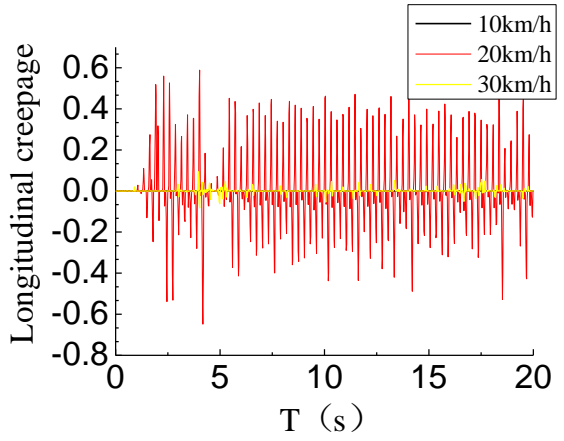

Fig.6 longitudinal creep age

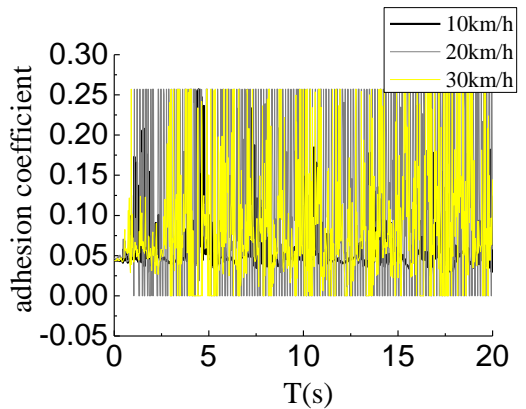

Fig.7 adhesion coefficient

\section{Impact of Longitudinal Flutter to the Force on Wheel/rail Contact Area and Wheel/rail Contact Patch Relative Sliding}

There are two possibilities of external stimulus to longitudinal flutter: track irregularity or wheel/rail contact patch. However, when remove track irregularities it also occurs longitudinal flutter at $20 \mathrm{~km} / \mathrm{h}$, shown in Fig.8, the impact of whee/rail contact patch is the original reason to longitudinal flutter, moreover, formation of longitudinal flutter is a process of time.

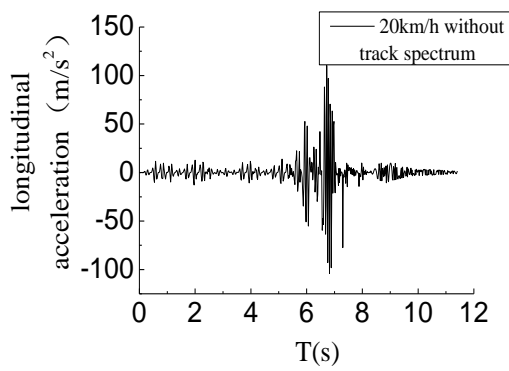

Fig.8 longitudinal acceleration

A. Impact on the force of wheel/rail contact area

Fig.9 shows the longitudinal creep force $3 \sigma$ value changes with different speeds, when the longitudinal flutter occurs, the wheel-rail contact area longitudinal creep force $3 \sigma$ value will increase significantly, leading to slippage. 


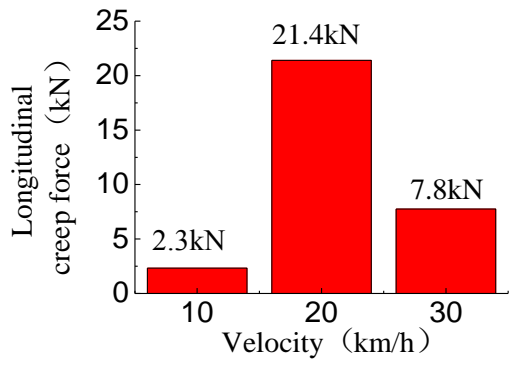

Fig.9 $3 \sigma$ value of longitudinal creep force at different speeds

\section{B. Impact on wheel/rail contact patch relative sliding}

Ideally wheel/rail contact patch is an ellipse, which is divided into the sliding area and adhension area, the relative size change of adhension area is the wheel-rail contact patch relative slippage which is to be studied.Throuth simulation the shape change of the wheel/rail contact patch when longitudinal flutter occurs, the contact patch adhesion area nearly disappear, shown as Fig.10, which means relative sliding is very large.

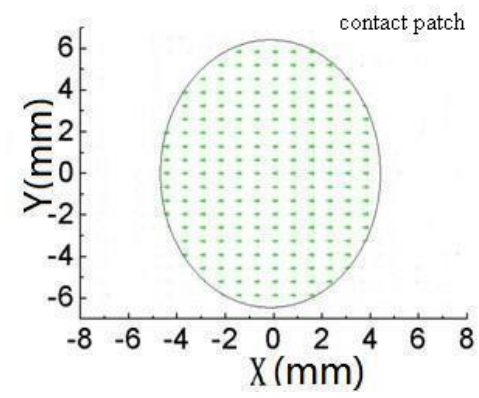

Fig.10 the shape of the contact patch

\section{Conclusion}

In this paper, we simulate the single wheel-set dynamics simplified model, we can get:

1) Longitudinal flutter occurs at specific speed;

2) Offer a similar criterion to predict a vehicle will occur longitudinal flutter or not before starting operation.

3) Gives an approximate criterion to calculate flutter dangerous speed, and verify the necessary to consider the longitudinal velocity component;

4) Longitudinal creep age and adhesion utilization coefficient is increased exponentially when longitudinal flutter occurs;

5) Longitudinal flutter has significant influence on wheel/rail contact area, which include increase the wheel/rail contact area creep force and very large wheel/rail contact patch relative sliding;
6) The mechanism of wheel-set longitudinal flutter is the coupling of wheel/rail contact patch excitation frequency and wheel natural frequency.

\section{Acknowledgment}

The paper was completely performed at Southwest Jiaotong University and it is supported by National Natural Science Foundation and Youth Science funded Projects. Some important instructions from Shihui Luo when analyze the simulation results. During the project, Zhenjun Li have offered some literature.

\section{References}

[1] NIELSEN, J. C. O, JOHANSSON, A. Out-of-round railway wheelsliterature survey. IMECHE Journal of Rail and Rapid Transit. 2000, 214 (F): 79-91.

[2] Zhang Bin, Fu Xiuqin. Type of railway wheel hub tread spalling and mechanism of formation. China Railway Science.2001, (2): 73-78.

[3] Shihui Luo, Dingchang Jin, Qing Chen. Wheel set longitudinal dynamics: A phenomenon yet to be proven. Railway Locomotive Dynamic Simulation Conference, Beijing: China Railway Society Vehicle Commission, 2004: 42-51.

[4] Luo Shihui, Jin Dingchang, Chen Qing. Study on longitudinal vibration of wheel sets and related problems of rail vehicles. Journal of the China Railway Society.2005, 27(3): 26-34.

[5] Luo Shihui, Song Xiaowen. SR-1 Self-steering radial bogie wheel tread peeling analysis and corrective measures. Electric Locomotives \& Mass Transit Vehicles. 2007:59-62.

[6] Ma Weihua, Luo Shihui, Wang Zili. Research on wheel tread spalling with the raising speed locomotive. Electric Locomotive and Transit Vehicles, 2005,(5):37-41,54.

[7] S.Chatterjee. Self-excited oscillation under non-linear feedback with time-delay. Journal of Sound and Vibration. 2011: 1860-1876.

[8] Wang Wei, Zeng Jing, Luo Ren. Present Conditions of Survey of Outof-Round Railway Wheels. Foreign Rolling Stock.2009 (1):39-44.

[9] Jin Xuesong, Shen Zhiyun, Development of Rolling Contact Mechanics of Wheel/rail Systems. Advances in Mechanics .2001, 31(1):33-46.

[10] Peng Wan, Wanming Zhai, Kaiyun Wang. Analysis of Running Stability of Vehicles with the Consideration of Wheel set Elasticity. Rolling Stock .2008 (6):8-10.

[11] P. MEINKE, S. MEINKE. Polygonalization of Wheel Tread Caused by Static and Dynamic Imbalances. Journal of Sound and Vibration. (1999) 227(5).

[12] Weihua Ma, Shihui LUO, Rongrong SONG. Influence of Different Wheel Coupling Mode to Wheel-set Longitudinal Vibration. The First International Conference of Transportation Engineering, Chengdu, China. July 22-24.2007

[13] Zhang Limin. Stick-Slip Vibration Analysis of Constrained Wheel set. Journal of Southwest Jiaotong University.1999, 34 (3):274-278.

[14] Ma Weihua.2007/11/1, wheel longitudinal vibration impact studies and related dynamics, Ph.D. vehicle engineering, Southwest Jiaotong University, China.

[15] Muller,P.C, Schiehlen,W.O. Forced Linear Vibrations. 1989.09:1-322

[16] Luo Shihui, Jin Dingchang, Chen Qing. Study on Longitudinal Vibration of Wheel Sets and Related Problems of Rail Vehicles.Journal of China Railway Society. 2005, 27(3):26-34.

[17] Nagase Kazuhiko. Research on the adhesion phenomenon. China Academic Journal Electronic Publishing House.1988:15-20

[18] Song Xiaowen. Numerical Simulation and Mechanism Analysis of Longitudinal Flutter of Single Wheel-set. Electric drive for Locomotive .2007 (5):18-21. 